\title{
Simulating Long Waves in a Coffs Harbour 3D Physical Model Using Short Wave Spectra
}

Indra FW Jayewardene ${ }^{1}$, Ed Couriel ${ }^{1}$, Oliver Light ${ }^{2}$, Mark Kulmar ${ }^{1}$ and Malcolm Robertson ${ }^{3}$

1. Manly Hydraulics Laboratory (MHL), NSW Public Works, Sydney, AUSTRALIA

2. Formerly MHL, now AECOM, Sydney, AUSTRALIA

3. Coffs Harbour City Council, Coffs Harbour, AUSTRALIA

\begin{abstract}
This paper presents examples of field data of extreme seiche waves measured at Coffs Harbour by MHL and describes the generation and measuring methodology to detect and reduce seiche agitation in the Coffs Harbour boat ramp using a 3D physical model. The paper also discusses the techniques in investigating a short wave problem of stability in the same model where a long wave is simulated. Waves offshore of Coffs Harbour at $80 \mathrm{~m}$ depth have been recorded by MHL for a period of over 30 years. Long waves have been simultaneously measured in the harbour over a period of a decade. These data enabled the model to be verified on two dates (4/6/12, 5/9/14) when high long waves were recorded at the boat ramp harbour under storm and non-storm conditions. Long waves are generated in harbours due to group bounded long wave and surf beat or edge waves. The paper presents methodologies of generating long waves both numerically and by using physical models, and discusses the advantages and disadvantages of these generation techniques. Numerical modelling carried out using long period regular waves in a previous investigation predicted reductions up to $50 \%$ due to change of planform of the boat ramp harbour where an area next to the boat ramp was excavated and roughness elements introduced to dampen long periods. The 3D physical model simulated a $25 \%$ decrease in the long wave energy in the boat ramp when a suitable change in the planform was made. A 3D undistorted model of scale 1:58 was used in the investigation.
\end{abstract}

Key words: Seiche, group bounded long waves, surf beat, planform.

\section{Introduction}

Coffs Harbour is situated on the mid-north coast of New South Wales approximately 600 kilometres north of Sydney. The timber jetty was constructed in 1892 when this was an important timber production area. The harbour was created by linking two offshore islands by breakwaters and filling a causeway. Harbour works commenced in 1912, connecting Muttonbird Island via the northern breakwater in 1924, South Coffs Island in 1929, the eastern breakwater and extension in 1965, completion of the northern inner harbour and southern boat ramp in 1978 (Fig. 1).

In port and harbour engineering, the term seiching is the amplification of certain low frequencies due to

Corresponding author: Indra FW Jayewardene, BSc, MSc, MIE (Australia), Senior Engineer, research fields: coastal processes, wave and structure interactions. the geometry of the basin and resonance is the process behind the phenomena. Long period waves are characterised by wave periods of between 0.5 and 30 minutes. NSW Public Works MHL (Manly Hydraulics Laboratory) was engaged by CHCC (Coffs Harbour City Council) in May 2014 to undertake a review of reporting on numerical modelling completed by Water Technology [1] on strategies to reduce wave seiching at the boat ramp at Coffs Harbour (Figs. 1, 2a and 2b). A 3D undistorted physical model of scale 1:58 was utilised to verify the numerical modelling results.

Long waves are generated due to group bounded long wave and surf beat or edge waves [2-4], and could include influences of the East Australian Current and density stratifications. Long waves propagating in coastal areas can amplify in semi-enclosed basins such as harbours and lagoons. This 


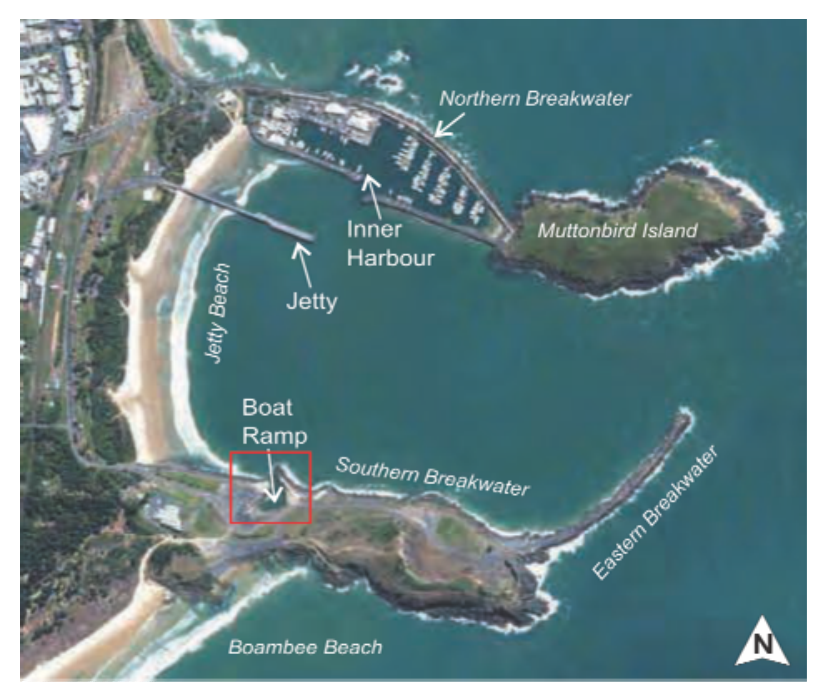

Fig. 1 Coffs Harbour indicating location of boat ramp.

occurs when the period of the incident wave is similar to the period of the forced oscillation, i.e. under resonance conditions. In the physical model long waves were generated using (1) an impulse function similar to that simulated in the breakwater modelling [5]; (2) a 125 s Jonswap spectrum to force the simulation of seiche in the boat ramp; and (3) group bounded short waves and/or surf beat. Short waves offshore of Coffs Harbour at $80 \mathrm{~m}$ depth have been recorded by MHL for a period of over 30 years. Long waves have been simultaneously measured in the harbour over a period of 25 years (Tables 1 and 2). These data enabled the model to be verified on two dates (4 June 2012 and 5 September 2014) when high long waves were recorded in the boat ramp harbour (Figs. 2a and 2b). Repair and maintenance issues associated with seiche energy within the harbour have been recognised previously [6]. This included the fact that within the harbour, seiche could occur on days of both high and low offshore wave activities.

Subsequent to verification, the model long wave agitation was reduced in the boat ramp harbour by $25 \%$ using a change of planform. Numerical modelling carried out in a previous investigation predicted reductions up to $50 \%$ due to change of similar planform of the boat ramp harbour.

\section{Historic Field Measurement of Long and Short Waves that Cause Seiche}

Table 1 provides a history of long wave measurement in Coffs Harbour.

A sample of the highest long waves measured during 1988-1992 is provided in Table 2. Although these two locations of historic measurement are not in close proximity to the boat ramp they provide evidence for long wave oscillations in the harbour).

Table 2 indicates that seiche periods of approximately 712 s, 138 s, 109 s, 66 s and 62 s were detected inside Coffs Harbour (depending on the

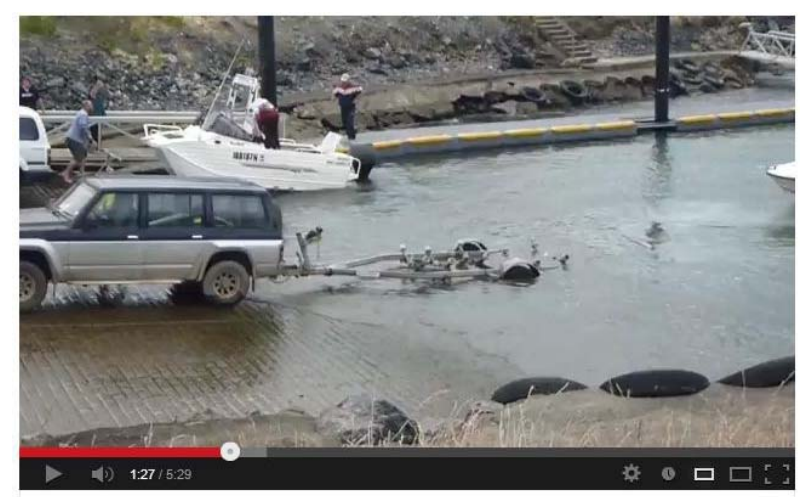

Fig. 2a $128 \mathrm{~s}$ seiche at boat ramp, T = 87 s, June 2012 .

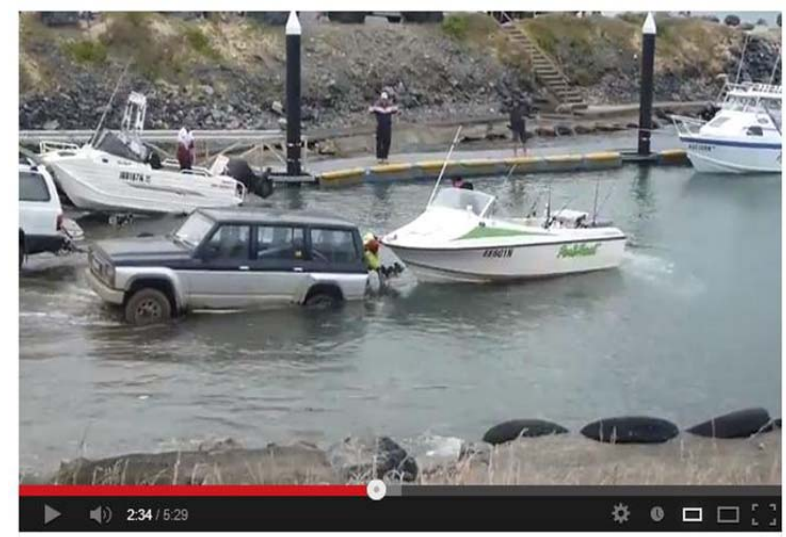

Fig. 2b 128 s seiche at boat ramp, $T=154$ s, June 2012 where launching vehicle is swamped.

Table 1 Long Wave Measurement History at Coffs Harbour (Source: DWAVE Archive).

\begin{tabular}{llllll}
\hline Site & Instrument & Water Depth $(\mathrm{m})$ & First date/Last date & Record Length (yrs) & Data Capture (\%) \\
\hline Coffs Jetty & Electronic Wave Staff & 7 & $5 / 11 / 86-15 / 1 / 96$ & 9.2 & 83.7 \\
Coffs Inner Harbour Electronic Wave Staff & 4 & $16 / 1 / 96-8 / 10 / 11$ & 15.74 & 83.8 \\
\hline
\end{tabular}


Table 2 Highest Long Waves Measured at Coffs Harbour Jetty During 1988-92 (Source: DWAVE archive MHL).

\begin{tabular}{lllll}
\hline Date/Time & $\mathbf{H}_{\mathbf{S}}(\mathbf{m})$ & $\mathbf{H}_{\text {MAX }}(\mathbf{m})$ & TP1 $^{*}(\mathbf{s})$ & TP2 $^{* *}(\mathbf{s})$ \\
\hline 9/02/1988 22:00 & 0.53 & 0.99 & 712 & 98 \\
15/05/1990 18:00 & 0.49 & 0.82 & 712 & 109 \\
15/05/1990 22:00 & 0.46 & 0.84 & 712 & 138 \\
16/05/1990 4:00 & 0.42 & 0.82 & 712 & 109 \\
26/04/1989 8:00 & 0.40 & 0.62 & 712 & 62 \\
23/10/1992 18:00 & 0.49 & 0.94 & 109 & 66 \\
9/03/1988 22:00 & 0.48 & 0.91 & 109 & 138 \\
10/02/1988 0:00 & 0.48 & 0.77 & 109 & 138 \\
22/10/1992 16:00 & 0.47 & 0.88 & 109 & 62 \\
15/05/1990 20:00 & 0.46 & 0.84 & 109 & 712 \\
\hline
\end{tabular}

*peak energy period ** secondary peak energy peak period.

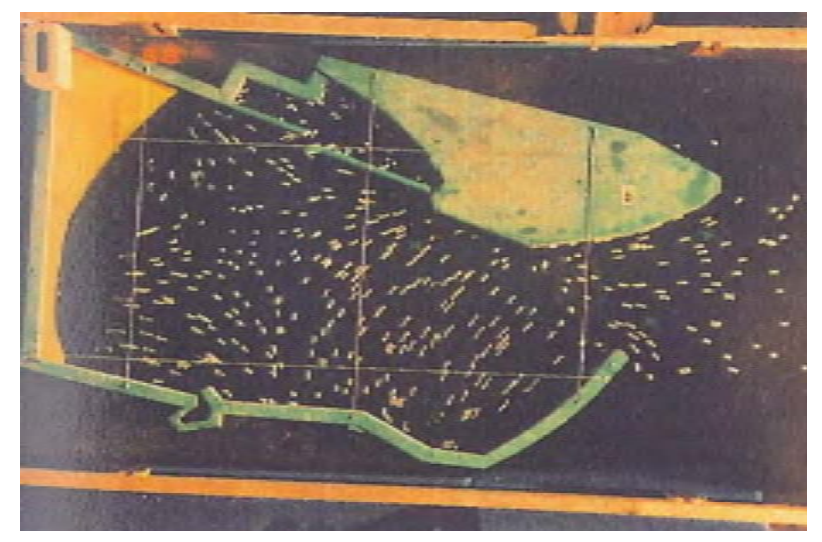

Fig. 3a Identifying modes of oscillation [9].

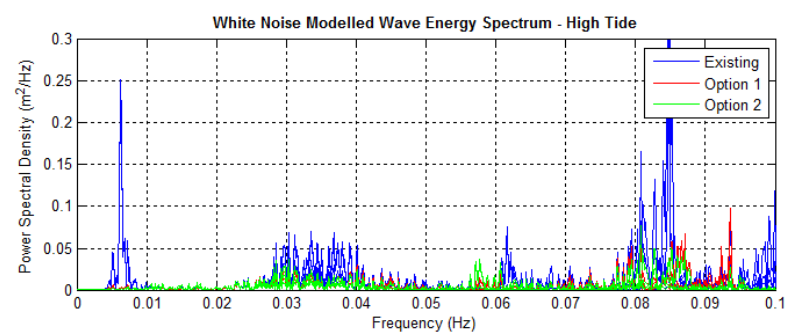

Fig. 3(b) White noise modelling carried out by Water Technology [1] to identify natural frequencies in Coffs Harbour.

parameters of the Fast Fourier Transform). The length of record is approximately 50 minutes. These $700 \mathrm{~s}$ waves are also mentioned in a published paper [6], where the coincidence between storm waves (Hs > 4.0 m) measured offshore of Coffs Harbour and high long waves (Hmax $>0.6 \mathrm{~m}$ ) inside the harbour was noted. However, it was also noted in this that on several days high long wave activity was recorded when no offshore storm waves ( $\mathrm{Hs}<3 \mathrm{~m}$ ) were recorded. A previous physical model study on seiche in the harbour (MHL 538 Fig. 3a) identified a $136 \mathrm{~s}$ and a $216 \mathrm{~s}$ long wave recorded at the jetty during the period July 1987 and March 1988.

\section{Previous Investigations}

3D physical modelling was carried out at MHL [5] (Fig. 3a) in order to identify seiche modes. This modelling was carried out at very small scales $(\mathrm{H}=$ $1: 800, \mathrm{~V}=1: 100)$ as there were no associated short wave problems to be solved in the model and the criteria for accurately simulating diffracted waves was not critical. Water Technology carried out white noise simulation (Fig. 3b) to identify long wave periods that resonated in the harbour at $160 \mathrm{~s}$, similar to numerical modelling that had been carried out by Koefod-Hansen [7].

\section{Long Wave Forcing Mechanisms}

Bowers [3] used a Stokes expansion to obtain a relationship relating the significant height of a measured long wave (Hsl) to the forcing mechanism generating the long wave.

If the long waves at the site are more bounded wave-group dominated then it could be assumed that Hsl $\sim(\mathrm{HsTp})^{2}$, whereas surf beats with unbroken grouped waves reflecting off Jetty Beach are more likely to be $\sim(\mathrm{HsTp})$.

\section{Modes of Oscillation in Harbour}

The period of oscillation of a seiche in a closed 
rectangular basin is given by:

$$
\mathrm{T}=\frac{2 / \mathrm{c}}{\sqrt{\left(\frac{\mathrm{n}}{\mathrm{b}}\right)^{2}+\left(\frac{\mathrm{m}}{\mathrm{l}}\right)^{2}}}
$$

where:

$T=$ period of oscillation in seconds;

$L=$ length of basin;

$B=$ width of basin;

$C=\sqrt{ }($ gd $)=$ shallow water celerity;

$D=$ basin depth;

$m$ = number of nodal lines across the basin length;

$n=$ number of nodal lines across the basin width.

The eight lowest modes of oscillation for a closed rectangular basin were calculated using a basin length (l) of 1,125 m, a basin width (b) of $625 \mathrm{~m}$ and a basin depth (d) of $8 \mathrm{~m}$ for Coffs Harbour and a length of 70 $\mathrm{m}$, a width of $40 \mathrm{~m}$ and depth of $1.5 \mathrm{~m}$ for the boat ramp basin, and are given in Table 3.

\section{The Physical Model}

\subsection{Basin Layout, Model Scales and Test Objectives}

MHL utilised its $18 \times 30 \mathrm{~m}$ wave basin with a directional wave generator paddle to set up the Coffs Harbour 3D physical model (Figs 4a and 4b).The wave paddle was positioned to provide calibration waves from between $90^{\circ}$ and $100^{\circ}$ (Fig 4b). Seven wave-probe locations were selected to measure both the incoming (offshore) short wave spectra generated from the directional wave paddle and long waves at various locations around the harbour, including at the

Table 3 Possible Periods of Oscillation in Coffs Harbour and Boat Ramp Basin.

\begin{tabular}{|c|c|c|c|}
\hline \multicolumn{2}{|c|}{ Nodal Parameter } & \multicolumn{2}{|c|}{ Oscillation Period (s) } \\
\hline $\mathbf{M}$ & $\mathbf{n}$ & Main Harbour & Boat Ramp Basin \\
\hline 1 & 0 & 254 & 36 \\
\hline 0 & 1 & 141 & 21 \\
\hline 1 & 1 & 123 & 18 \\
\hline 2 & 0 & 127 & 18 \\
\hline 0 & 2 & 71 & 10 \\
\hline 2 & 1 & 94 & 14 \\
\hline 1 & 2 & 68 & 10 \\
\hline 2 & 2 & 62 & 9 \\
\hline
\end{tabular}

jetty, within the marina and both inside and outside the boatramp basin (Fig 4a).

\subsection{Test Objectives}

The following scope of works for the 3D physical model testing was developed by NSW Public Works MHL in collaboration with CHCC project representatives:

- undertake preliminary model setup testing to

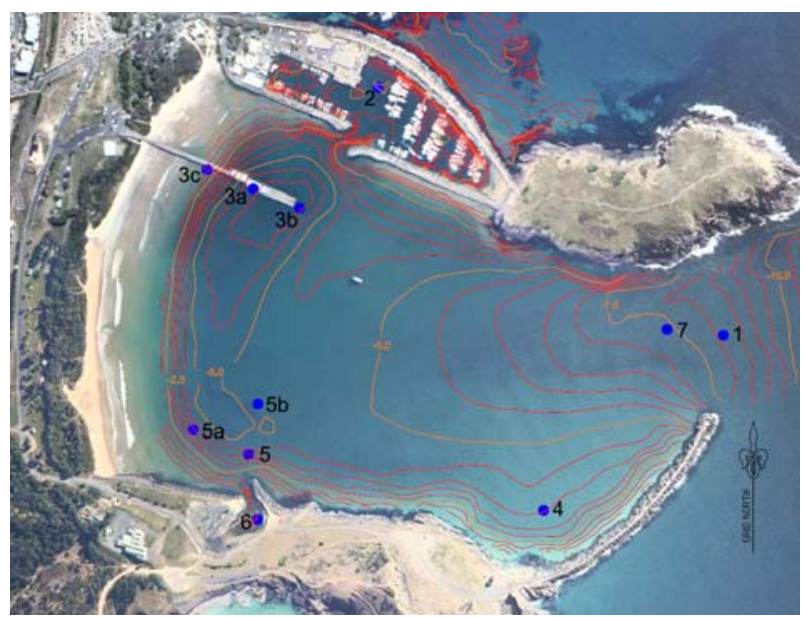

Fig. 4a Basin layout indicating probe positions and planform extension. The probe position 5 was varied to accommodate the possible $15 \mathrm{~m}, 30 \mathrm{~m}$ and $50 \mathrm{~m}$ boat ramp breakwater extensions. Probe 6 is at boat ramp.

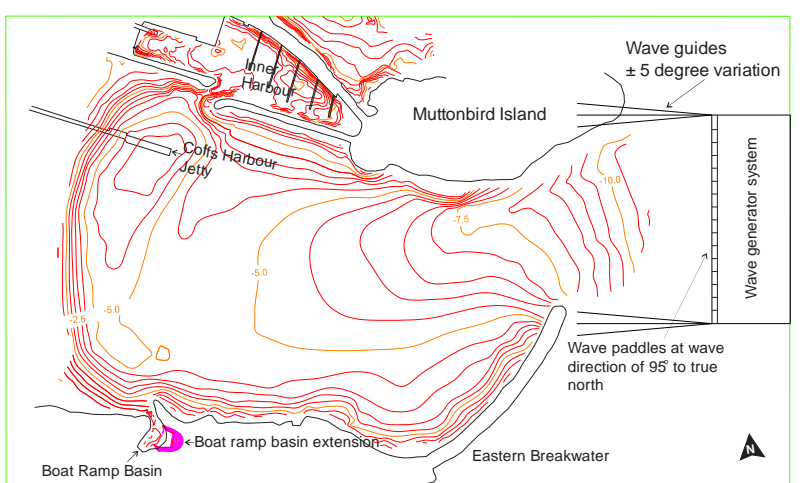

Fig. 4b Basin layout indicating wave generator boat ramp basin extension and change of planform in pink.

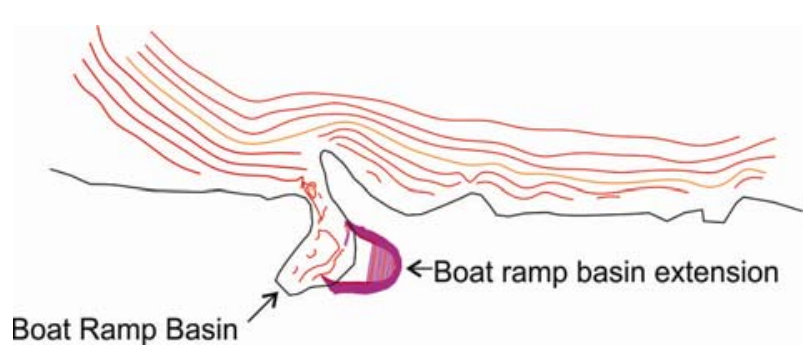

Fig. 4c Schematic of boat ramp modification. 
generate seiching activity in the main Coffs Harbour basin, inner basin and boat ramp basin;

- develop an initial test program to validate seiche behaviour in the boat ramp basin in June 2012 and September 2014;

- test the model for seiche activity in the existing boat ramp basin for a range of offshore wave conditions and two water levels (mean sea level and high tide level);

- incorporate and test Water Technology/Geolink [1] Option 2 boat ramp basin extension configuration into the physical model layout;

- compare the results of the seiche activity for the existing boat ramp basin and the Option 2 basin extension layout to determine the reduction in seiche activity provided by the extended boat ramp basin configuration.

Several investigations have provided indicators of the limiting size of models for reduced Reynolds number effects or scale effects [8]. More recently Cornett [9] determined a condition for negligible scale effect.

\subsection{Model Scales}

A length scale of 1:58 was selected for the Coffs Harbour 3D physical model. The scale is determined considering the dimensions of the structures to be modelled, the requirement to model armour stability, water levels, wave heights and the need to minimise scale effects in a model that requires adequate model dimensions to measure the small wave heights simulated in the model. The time scale was determined from the length scale using Froudian similitude. The mass scale allows for the differences in density between sea water in the prototype and fresh water used in the model. The Hudson methodology was utilised to obtain the mass scale [10].

The model scales selected for the study were:

Length scale $\left(\mathrm{L}_{\mathrm{r}}\right)=58$

Time scale $\left(\mathrm{T}_{\mathrm{r}}\right)=\sqrt{\mathrm{L}_{\mathrm{r}}}=7.61$

Mass scale (Rock Armour) $\left(\mathrm{M}_{\mathrm{r}}\right)=219,962$

where the mass scale was obtained by utilising the stability number criterion:

$$
M_{r}=\left(H_{p} / H_{m}\right)^{3}\left(\rho_{p} / \rho_{m}\right)\left(\Delta_{m} / \Delta_{p}\right)^{3}
$$

where

$H_{p}$ is height in the prototype;

$H_{m}$ is height in the model;

$\rho_{p}$ is density of rock in the prototype;

$\rho_{m}$ is density of rock in the model;

$\Delta_{m}$ is the specific density of water in the model;

$\Delta_{p}$ is the specific density of water in the prototype.

A comprehensive discussion on scale effects in models and measurements required to mitigate these errors is provided in Ref. [10]. Scale values that resulted in Re numbers greater than 20,000 were selected in order to satisfy Cornett's [9] criteria when testing the stability of 4 tonne rock armour to minimise scale effects in the physical model investigations.

\subsection{Test Results}

Table 4 provides details of tests carried out at two water levels and indicates a 23\%-29\% reduction in Hsl

Table 4 Possible Periods of Oscillation in Coffs Harbour and Boat Ramp Basin-Probe 6.

\begin{tabular}{llllllllll}
\hline $\begin{array}{l}\text { Water } \\
\text { Level } \\
\text { (m AHD) }\end{array}$ & \multicolumn{2}{c}{ Harbour Entrance } & \multicolumn{2}{c}{ Existing Basin } & \multicolumn{2}{c}{ Extended Basin } & \multicolumn{2}{c}{$\begin{array}{c}\text { Extended Basin (with } \\
\text { Roughness) }\end{array}$} & $\begin{array}{l}\text { Maximum } \\
\text { Hsl Reduction } \\
\text { (\%) }\end{array}$ \\
\cline { 2 - 9 } & Hsig (m) & Tp1 (s) & Hsl (m) & TP1 (s) & Hsl (m) & TP1 (s) & Hsl (m) & TP1 (s) & 24.5 \\
0.0 & 4.12 & 17.2 & 0.45 & 125 & 0.39 & 207 & 0.34 & 623 & 23.9 \\
0.8 & 3.66 & 17.2 & 0.46 & 125 & 0.38 & 104 & 0.35 & 125 & 23.2 \\
0.8 & 4.40 & 16.4 & 0.56 & 207 & 0.43 & 138 & 0.44 & 125 & 29.7 \\
0.8 & 4.81 & 15.8 & 0.64 & 125 & - & - & 0.45 & 125 & 25.0 \\
0.8 & 2.78 & 13.2 & 0.44 & 104 & - & - & 0.33 & 104 & 24.4 \\
0.8 & 2.30 & 13.1 & 0.41 & 113 & - & - & 0.31 & 123 & 24.0 \\
0.8 & 1.38 & 13.3 & 0.25 & 104 & - & - & 0.19 & 144 & \\
\hline
\end{tabular}




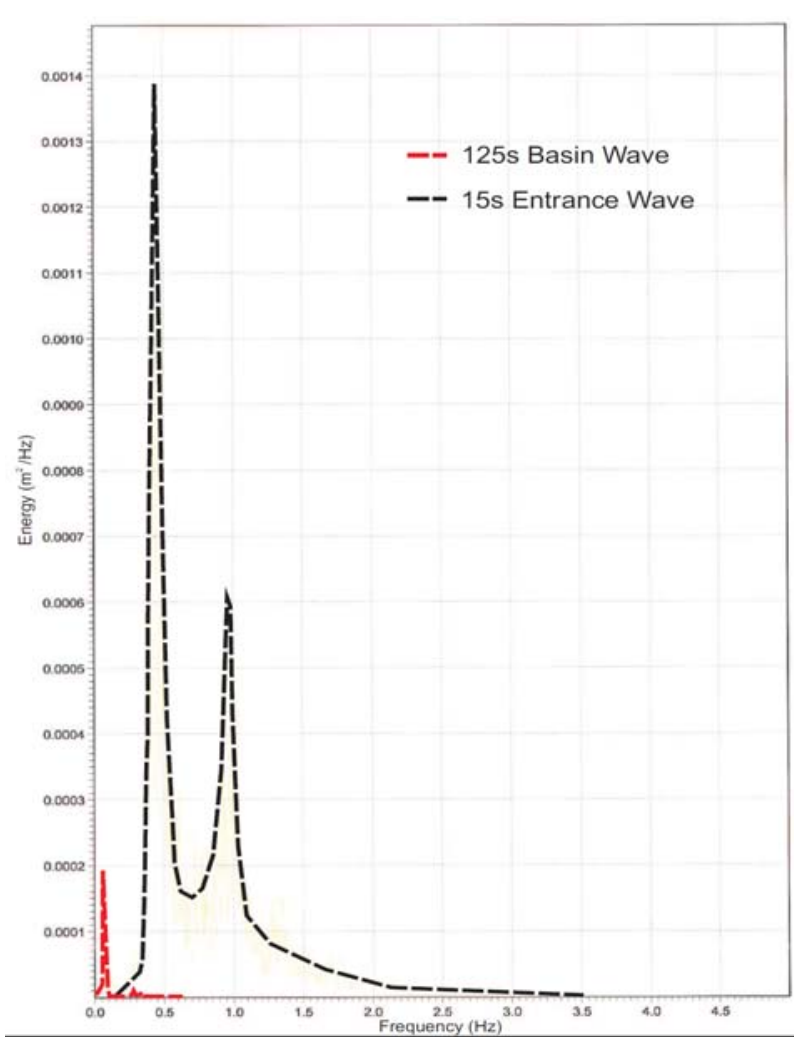

Fig. 5a Indicating long wave spectrum in Probe 6 in the boat ramp basin.

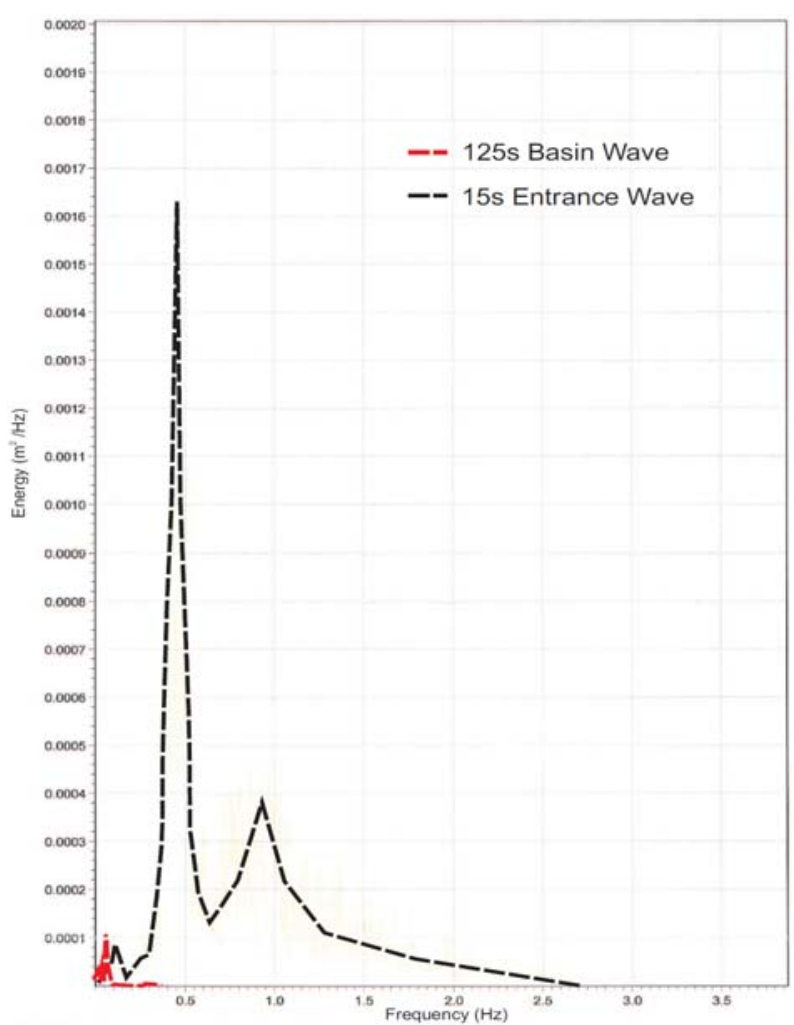

Fig. 5b Indicating long wave spectrum energy reduction in Probe 6 by $25 \%$ after basin modification.

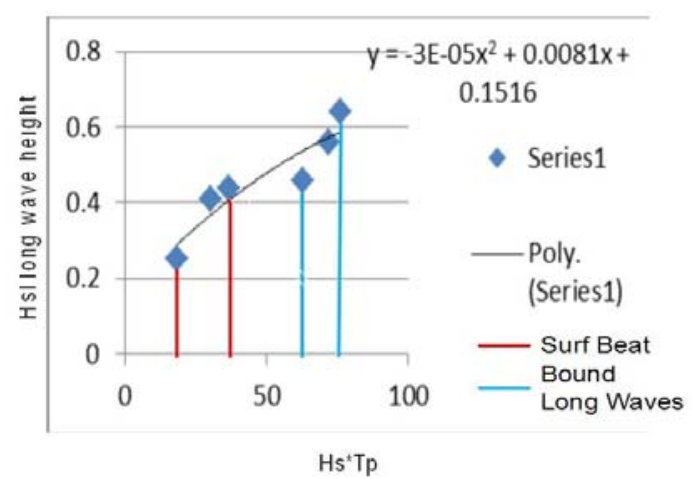

Fig. 5c Graph of seiche wave energy indicating relationship with beat surfbeat and bounded long waves [3].

due to change in planform of the boat ramp basin.

\subsection{Measurement of Long Waves in the Model}

Two methods were utilised to measure long waves: (1) runup along the boat ramp, clearly indicating the seiche period, and (2) water level measurement resulting in a Fourier spectrum as indicated in Figs. 5a and $5 \mathrm{~b}$. Adequate lengths of time series (1,350 s) were recorded in order to obtain sufficient resolution of the long periods in the Fourier spectrum. Figs. $5 \mathrm{a}$ and $5 \mathrm{~b}$ indicate a reduction of $25 \%$ in long wave energy for the same spectral short wave energy measured at the harbour entrance due to the changed planform of the boat harbour and the resulting increase in area. Fig. 5c indicates that the forcing function for seiche generated in the boat ramp basin in the model most likely would be due to surf beat (Hsl (HsTp)) generated by grouped waves reflecting off Jetty Beach during non-storm conditions and group bounded waves $\left(\mathrm{Hsl} \sim(\mathrm{HsTp})^{2}\right)$ during storm conditions. However, more investigation would have to be carried out on this aspect of seiche generation within the harbour to provide a more definitive understanding.

\section{Discussion}

A simplified rectangular model indicates that the planform of Coffs Harbour has the dimensions to resonate at periods 120-130 s.

Historic field data collected at Coffs Harbour for a decade indicates that both bounded waves caused by 
high offshore waves and surf beat or edge waves resulting from smaller wave groups reflecting off Jetty Beach may result in seiche periods of 120-130 s within the boat harbour.

Impulse function testing (white noise) and testing with a $129 \mathrm{~s}$ Jonswap spectra gave rise to a $100 \mathrm{~s}$ to $150 \mathrm{~s}$ waves in the boat ramp.

Water level conditions at $0.0 \mathrm{~m}$ AHD and $0.8 \mathrm{~m}$ AHD were tested with 12-15 s Jonswap spectra which included the offshore conditions recorded in June 2012 and September 2014 at which time a $125 \mathrm{~s}$ seiche was observed in the boat ramp harbour and was used to verify the model. The model was undistorted and the scale was 1:58.

Testing of the above conditions with basin modified to increase friction resulted in less than $30 \%$ reduction in long wave energy in the modified boat ramp. A reduction of greater than $50 \%$ as forecast by the numerical modelling was not observed.

Stability testing of the possible $15 \mathrm{~m}, 30 \mathrm{~m}$ and 50 $\mathrm{m}$ boat ramp breakwater extensions utilising $15 \mathrm{~s}, 6 \mathrm{~m}$ waves at the entrance resulted in low damage to 4 tonne armour. The $50 \mathrm{~m}$ extension ( $5^{\circ}$ to north) did not provide added protection when compared to the original testing that was carried out at $335^{\circ}$. The possible breakwater extensions in general did not result in any significant long wave attenuation within the boat harbour.

\section{Acknowledgements}

The authors wish to thank Manly Hydraulics Laboratory and Coffs Harbour City Council for permission to utilise data from published reports.

\section{References}

[1] Water Technology/Geolink 2014. Coffs Harbour Boat Ramp Basin Improvement Design." Water Technology/Geolink Report 2954-01/R01, 201.

[2] Baldock, T. E., and Huntley, D. A. 2002. "Long-Wave Forcing by the Breaking of Random Gravity Waves on a Beach." Proc. Royal Society, London. 458: 2177-201.

[3] Bowers, E. C. 1992. "Long Period Disturbance Due to Wave Groups.” Proceedings 23rd Int. Conf. Coastal Engineering, 832-45.

[4] Dean, R. G., and Dalley, W. R. 1986. "Transformation of Random Waves Breaking on Surf Beat.” 20th ICCE Conference, 109-23.

[5] Manly Hydraulics Laboratory. 1989. Coffs Harbour Seiche Study - A Physical Model Study on the Existing Harbour and Field Data Review. Manly Hydraulics Laboratory, Report No. 538.

[6] Jayewardene, I. F. W., and Rangger, H. 2001. "Repair and Maintenance Issues Raised by Short and Long Wave Disturbance Inside Coffs Harbour.” 15th Australasian Conference on Coastal and Ocean Engineering, Institution of Engineers Australia.

[7] Kofoed-Hansen, H., Kerper, D. R., Soresen, O. R., and Kirkegaard, J. 2005. "Simulation of Long Wave Agitation in Ports and Harbours Using a Time Domain Boussinesq Model.” Proceedings of Fifth International Symposium on Ocean Wave Measurement and Analysis, WAVES 2005 Madrid, Spain.

[8] Dai, Y. B., and Kamel, A. M. 1969. Scale Effect Tests for Rubble Mound Breakwaters. Waterways Experiment Station, Research Report H-69-2, Department of the Army, USA.

[9] Cornett, A. 1995. "A Study of Forcing and Damage of Rock Armour on Rubble Mound Breakwaters.” Ph.D. Thesis, Technical Report HYD-TR-005, National Research Council, Canada.

[10] Hughes, S. A. 1993. Physical Models and Laboratory Techniques in Coastal Engineering. Advanced Series on Ocean Engineering 7. 